\title{
Distribuição da população brasileira sob o enfoque das cidades de porte médio
}

\author{
Cristiano Stamm* \\ Manoela Silveira dos Santos**
}

\begin{abstract}
Resumo
A desconcentração industrial, a mobilidade da fronteira agrícola e os investimentos em infra-estrutura que integraram o interior do Brasil à dinâmica da economia nacional são apontados como um dos fatores responsáveis pela dispersão espacial da população brasileira. $\mathrm{O}$ presente artigo mostra a evolução das cidades de porte médio no Brasil entre os períodos de 1970 a 2010 a partir de um enfoque populacional. A metodologia é caracterizada por pesquisa documental. Ao longo do estudo, é possível observar que as cidades de porte médio têm uma posição estratégica potencial para a continuidade da desconcentração regional no Brasil. Os resultados apontaram que as cidades de porte médio aumentaram sua participação na população total do país, o que em 1970 era representado por cerca de $18 \%$ da população urbana, em 2010 chegou a abrigar pouco mais de $27 \%$ dessa população.
\end{abstract}

Palavras-chave: População urbana; Cidades de porte médio; Sistema urbano, Brasil.

* Doutor em Planejamento Urbano pela Ufrgs e Economista e Mestre em Desenvolvimento Regional e Agronegócio pela Unioeste/Campus de Toledo. Professor do Mestrado em Economia da Unioeste. Pesquisador do Grupo de Pesquisa em Agronegócio e Desenvolvimento Regional (Gepec). E-mail: stamm_br@yahoo.com.br

** Doutora e Mestre em Administração pela Universidade Federal do Rio Grande do Sul. Professora de Administração da Unioeste/Campus de Foz do Iguaçu. Pesquisadora do Grupo de Pesquisa em Agronegócio e Desenvolvimento Regional (Gepec) da Unioeste/Campus de Toledo. E-mail: manoelasantospoa@gmail.com

http://dx.doi.org/10.5335/rtee.v23i49.8257

Submissão: 28/09/2016. Aceite: 05/04/2017. 


\section{Introdução}

Este artigo analisa a evolução das cidades brasileiras de porte médio no período de 1970 a 2010 sob o enfoque populacional. Essa temática avança sobre um possível "novo papel" reservado às cidades brasileiras de porte médio na atual ordem econômica e social nacional/mundial. A escolha desses períodos deve-se a duas particularidades: a primeira é a insuficiência de centros urbanos intermediários com dinamismo demográfico e econômico na década de 1970; e a segunda está relacionada ao último Censo Demográfico do Instituto Brasileiro de Geografia e Estatística (IBGE), principal fonte de dados dessa análise.

Os dados populacionais do censo demográfico de 2010 revelaram a importância das cidades de porte médio brasileiras, evidenciando um processo de desconcentração populacional dos grandes centros. As cidades de porte médio deveriam intensificar as suas atenções em adotar políticas para organizar esse processo ou mesmo ampliar essa potencialidade à medida que: a) foram, até então, e desde a década de 1970, as grandes responsáveis pelo espraiamento espacial da população no país; e b) apresentam, ante os centros urbanos de menor porte, condições (vantagens locacionais) para sediar aqueles setores de atividade com "tendência à interiorização" (no sentido de estarem se retirando dos grandes centros urbanos) (Amorim Filho e Serra, 2001).

De acordo com Pereira (2005), um dos critérios mais utilizados na definição de cidades de porte médio tem sido a dimensão demográfica. Ainda de acordo com a autora, quando se debate sobre cidades de porte médio, trata-se mais de uma noção do que de um conceito. Dessa forma, para se alcançar o objetivo proposto neste artigo, optou-se pela classificação de cidades de porte médio como sendo o conjunto de cidades cuja população urbana residente situava-se entre $100 \mathrm{mil} \mathrm{e} 500 \mathrm{mil}$ habitantes, presentes nos censos demográficos de 1970 e 2010. Essa classificação é utilizada em trabalhos de autores como: Santos (2005), Braga (2005), Maricato (2001), Amorim Filho e Serra (2001), Brito, Horta e Amaral (2001), Andrade e Serra (2001a) e Lima (1998). Vale ressaltar que o foco está sobre as cidades de porte médio ao invés das cidades pequenas, porque é inevitável a necessidade de uma escala mínima urbana, mesmo sabendo que uma cidade de porte médio esteja fortemente associada à sua funcionalidade com seu em torno.

Considerando a vasta possibilidade de estratégias a serem adotadas para conduzir um estudo qualitativo e o objetivo a ser a pesquisado, optou-se por operacionalizar o estudo por meio de dados secundários. Além disso, a trabalho aproxima-se da pesquisa histórica por investigar os eventos que já ocorreram com a população

Teoria e Evidência Econômica - Ano 23, n. 49, p. 381-406, jul./dez. 2017 
e suas cidades, mais especificamente no que tange às mudanças e às alterações do tamanho e a quantidade de cidades, sendo operacionalizada por meio da pesquisa documental.

Além dessa parte introdutória, este artigo possui mais quatro seções: na segunda parte são feitos alguns apontamentos sobre território e hierarquia das cidades. Na terceira parte é abordada a questão sobre o processo de urbanização, procurando evidenciar alguns atributos às cidades de porte médio. A dispersão das cidades de porte médio pelo território nacional contempla a quarta parte do trabalho, em que são confeccionadas algumas tabelas e figuras e suas respectivas análises. As considerações finais sumariam este artigo.

\section{Território e hierarquia das cidades}

Embora o termo território tenha sido mais usualmente caracterizado com base em relações de poder e, dessa forma faz referência ao Estado-Nação, alguns pesquisadores têm apresentado essa definição a partir de outras variáveis importantes na produção do território.

Haesbaert da Costa (2004, p. 40) sintetiza essas variáveis e sinaliza em apenas três vertentes de conceitos para território, sendo: i) política ou jurídico-política: definido por delimitações de controle e poder, especialmente o de caráter estatal; ii) cultural ou simbólico-cultural: visto como produto da apropriação resultante do imaginário; iii) econômica: a qual enfatiza a dimensão espacial das relações econômicas, ou seja, o território é a fonte dos recursos, o que gera um confronto entre classes sociais e também da relação capital-trabalho.

Vale ressaltar que a noção de território da tradição jurídico-política tem como referencia autores clássicos como Friedrich Raztel, Claude Raffestin e Robert Sack. $\mathrm{Na}$ ótica ratzeliana, segundo Moraes (2000, p. 19 apud HAESBAERT DA COSTA, 2004, p. 62) "o território é um espaço qualificado pelo domínio de um grupo de humano, sendo definido pelo controle político de um dado âmbito espacial”. De acordo com Claude Raffestin e Robert Sack (apud HAESBAERT DA COSTA, 2004, p. 68), parece haver um consenso de que a dimensão política, além de sua perspectiva jurídica e estatal, é a que melhor responde pela conceituação de território.

Dessa forma, o território será entendido como espaço em que as relações sociais são conferidas historicamente. De acordo com a idéia de Santos (1999), o território usado pode ser adequado à noção de um território em mudança, de um território em processo. 
Todos esses elementos presentes na discussão do território possibilitam o desenvolvimento teórico e metodológico na compreensão da cidade, que está inserida numa economia globalizada, uma economia em busca de territórios racionais ${ }^{1}$.

A cidade é um importante local de vitalidade econômica, cultural e social, além disso, é o centro das decisões políticas. Ela é um fenômeno de aglomerados industriais, comerciais, financeiros, religiosos e de lazer da população, que procuram proporcionar seu bem-estar social, ou seja, é o que Castells (1983) denominou como sendo aglomerados funcionais. Por isso, as cidades, dentro de determinadas áreas podem ser classificadas hierárquica, normalmente, de acordo com suas funções econômicas. As faixas hierárquicas, geralmente, são expressas por uma divisão de classes de tamanhos de população. $O$ tamanho populacional das cidades pode indicar suas funções necessárias mínimas para satisfazer as necessidades dessa população.

As cidades de menor porte são tidas apenas como um centro mediador do comércio local com as regiões. As cidades de médio porte, além das funções das cidades de menor porte, apresentam um maior peso econômico e assumem a função de suprir as demandas dos produtos que não são produzidos nos centros de menor porte. As cidades de grande porte (ou metropolitanas) se distinguem pelo maior volume populacional, por serem polarizadoras de centros menores e caracterizam-se por apresentar uma mancha de ocupação derivada de conurbação (CHRISTALLER, 1966; GEDDES, 1994; IPEA et al. 1999).

Apesar das diferenças de tamanhos, as cidades relacionam-se entre si, assumindo diferentes tipos de relações no espaço, formando as redes de cidades. Para Ferrera de Lima (2004), a organização dessas redes serve para otimizar as economias de proximidades, ou seja, os meios de transporte, a distribuição da população e a oferta de bens de serviços. Essas redes refletem a organização e segmentação do espaço. Essas redes reorganizam o espaço criam novas aglomerações, novos centros, novas áreas de mercado baseadas sobre uma nova conjuntura econômica e potencial da produção. Em certos casos, conforme Lacour e Gaschet (2002), esses novos centros potenciais provém da integração periférica com um pólo, estimuladas pelo melhoramento das redes de transporte e comunicação, diminuindo as distâncias.

O papel do pólo e da periferia na organização da rede urbana não é atual. Os estudos clássicos de Friedman (1972) apontavam a hierarquia funcional das cidades, como segue: a) cidade primaz (primate city), que exerce funções de alta complexidade, com especialização em serviços de saúde e educação, equipamentos de precisão, financeiros, comunicações, governamentais e, também, como áreas que 
tenham maiores mercados potenciais; b) cidades regionais (regional city), polarizadas por centros de reconhecida importância na rede urbana regional (têm influências das cidades primazes) e apresentam uma abrangência de polarização mais restrita; c) cidades sub-regionais (provincial city), que são os centros comerciais inferiores, esporadicamente com alguns centros industriais; e d) cidades locais (local service city), exclusivamente agrícolas, com menor volume populacional e densidade, mas integradas por uma dinâmica socioeconômica comum. Podem surgir neste mesmo contexto hierárquico, cidades satélites direcionadas para economias mais simples ou atividades como manufatura, educação, entretenimento, administração entre outras.

Apesar da classificação de Friedman (1972), os avanços mais recentes nos mecanismos da polarização foram dados por Krugman (1991), com seus estudos da nova economia geográfica. Segundo Krugman (1991) e Krugman, Venables e Fujita (2004), a polarização é o resultado da interação entre baixos custos de transporte e de relações inter-industriais de cooperação e concorrência entre cidades específicas. Por isso, as cidades periféricas aliam custos expressivos de transporte com uma relação de dependência nas atividades de transformação e serviços. Isso faz com que as cidades periféricas tenham um custo maior de produção e distribuição aliada a problemas com retorno de escala. Com isso, custos moderados de produção associados aos retornos de escala e custos de serviços pouco significativos geram tendências à concentração geográfica dos agentes econômicos, conseqüentemente, no padrão de localização das atividades produtivas e na organização espacial da economia.

Essa discussão em torno da polarização nos remete a uma constatação: a cidade per si é um sistema que integra outro sistema mais complexo, mas devido às diferenças entre elas passam a coexistir lugares centrais de graus diferentes, cujo papel é estruturar e organizar o espaço geográfico e/ou geoeconômico de uma região. Por isso, no caso dessa análise as cidades serão classificadas como: a cidade primaz como um lugar central de ordem superior; as cidades locais como lugares centrais de ordem inferior e o restante das cidades (as cidades regionais e sub-regionais) como centros urbanos intermediários. Dessa forma, os centros urbanos tidos como intermediários serão, para efeito de análise, as cidades de porte médio, objeto desse artigo. 


\section{A evolução da urbanização no Brasil}

No Brasil, na década de 1970, os primeiros estudos sobre as cidades de porte médio definiam esses centros urbanos como aqueles que possuíam alguns atributos sistematizados por Amorin Filho (1984), tais como:

- Interações constantes e duradouras tanto com seu espaço regional subordinado quanto com aglomerações urbanas de hierarquia superior;

- Tamanho demográfico e funcional suficiente para oferecer um leque bastante largo de bens e serviços ao espaço microrregional e desenvolverem economias urbanas necessárias ao desempenho eficiente de atividades produtivas;

- Capacidade de receber e fixar os migrantes de cidades menores ou da zona rural, por meio do oferecimento de oportunidade de trabalho, interrompendo o movimento migratório na direção das grandes cidades, já saturadas;

- Condições necessárias ao estabelecimento de relações de dinamização com o espaço rural microrregional que envolve;

- Diferenciação do espaço intra-urbano, com um centro funcional já bem individualizado e uma periferia dinâmica, como as grandes cidades, isto é, por intermédio da multiplicação de novos núcleos habitacionais periféricos.

As cidades de população entre 50 mil e 250 mil habitantes englobariam todos os atributos requeridos acima. Porém, apesar dos elementos sistematizados por Amorim Filho (1984), ocorreram modificações nas funções típicas das cidades de porte médio, principalmente, devido às transformações e evoluções do sistema urbano vigente. Além disso, os limites demográficos na maioria dos estudos foram ampliados e o que definia cidades de porte médio não satisfaz mais a atual configuração socioeconômica. Assim, pode-se inferir que uma cidade de porte médio deve dar suporte a uma quantidade importante de atividades e serviços que exigem para existir uma população não inferior a 100 mil habitantes.

Compreender as transformações do território nacional quando retratamos as cidades, obriga-nos a retomar a singularidade da urbanização e as formas de integração que ela significara no processo da intensificação e da formação das metrópoles nacionais. Processo que causou uma intensa urbanização, baseado na concentração demográfica e econômica, principalmente entre o eixo Rio de Janeiro - São Paulo, além, é claro, de sua consequência direta sobre os migrantes e a parte pobre da população que lá se encontravam.

Para tanto, recorrer-se-á ao trabalho de Perlman (1977) a qual abordou em seu primeiro capítulo as controvérsias sobre a urbanização, em que segundo a 
autora esse fenômeno se processa a uma velocidade maior que a industrialização e a criação de instituições urbanas compatíveis como, novas oportunidades de trabalho, serviços urbanos, acomodações, infra-estrutura e capacidade administrativa da cidade, grande parte devido às elevadas taxas de migração, crescimento natural da população e/ou da supermecanização (uso de tecnologia e capital-intensivo nas indústrias, em detrimento da geração de novos postos de trabalho).

Num processo de construção histórica, Perlman (1977), ressalta que nos anos de rápida urbanização as cidades foram sendo invadidas por migrantes originários das zonas rurais. Ainda de acordo com Perlman (1977, p. 28), "imaginava-se que esses migrantes chegavam do interior, solitários e sem raízes, despreparados e incapazes de se adaptar perfeitamente à vida urbana, além de perpetuamente ansiosos por regressar aos seus vilarejos".

Ainda abordando o histórico do fenômeno da urbanização, Perlman (1977), cita que as cidades são datadas de 5.500 anos, e corroborando Munford (1982) descreve que foi nesse período em que as sociedades descobriram novas técnicas de produção e passaram a produzir mais que o necessário para sobrevivência, mas que as grandes populações urbanas ainda são um fato recente. Perlman (1977, p. 30) complementa, dizendo que nenhuma sociedade era descrita como sendo mais urbana que rural antes de 1850, e enfatiza que "apenas 1,7\% dos 900 milhões de habitantes no mundo em 1800 viviam em cidades com mais de 20.000 habitantes. Já entre 1800 e 1950, enquanto a população total do mundo aumentou 2,5 vezes, as populações urbanas aumentaram vinte vezes".

No Brasil, após a década de 1950, ampliou-se o número de cidades de porte médio, num contexto de redefinição do porte dos núcleos urbanos nacionais, devido principalmente pelo processo de industrialização da economia brasileira via substituição de importações, motivo o qual levou há um intenso fluxo migratório ou também o chamado "êxodo rural" para os grandes centros do país, além da falta de novas oportunidades de trabalho nas pequenas cidades, moldando desde então a rede urbana nacional.

Na década de 1960, o avanço da urbanização contribuiu para a criação das metrópoles nacionais, essas, institucionalizadas a partir da década 1970. Esse fenômeno pode ser explicado, basicamente, por meio da reestruturação do terceiro setor, ou seja, o setor de serviços começa a ganhar força (SCHAPIRA, 1999). Com isso, os serviços que davam suporte a estrutura industrial tornaram-se uma característica da dispersão dos centros urbanos. Assim, conforme relata Kon (1999), os economistas reconhecem que o setor de serviços é um fenômeno urbano e que em alguns estudos se referem a um forte relacionamento entre a proliferação dos serviços e ao amplo processo de urbanização. 
Ainda sobre o processo de urbanização no Brasil, Perlman (1977) enfatizou que o país contava com uma das mais altas taxas de crescimento urbano da América Latina, se tornando na década de 1970 um país predominantemente urbano. Segundo Maricato (2001), existe uma gama de autores que tratam das características concentradoras do processo da urbanização no Brasil, e também nos países da América Latina. Nesse contexto de urbanização, segundo a Comissão Econômica para América Latina e o Caribe - Cepal, os países que compõem a América Latina e o Caribe formam a

[...] región en desarrollo más urbanizada del mundo: 380 millones de personas viven en las ciudades y 127 millones en las zonas rurales, y su nivel de urbanización llegó a un 75\% en el 2000. Las ciudades tienen hoy enormes rezagos de infraestructura, institucionalidad y base productiva, además de una aguda desigualdad en la distribución de los bienes y servicios entre sus residentes. La "urbanización de la pobreza" es un fenómeno propio de la región, ya que en Asia y África la mayoría de los pobres aún vive en el campo (CEPAL, 2000, p. 1).

Conforme a Cepal (2000), cerca de 52 cidades, nessa região, apresentavam uma população superior a um milhão de habitantes no ano de 2000 e algumas dessas cidades são consideradas cidades globais pela sua densidade populacional e dinâmica econômica, pois são cidades de grande porte que chegam a abrigar mais de cinco milhões de habitantes. Já as cidades intermediárias (cidades de porte médio) mantiveram um dinamismo demográfico sobressalente. Se forem comparadas com as cidades de grande porte, elas apresentavam em muitos casos um maior potencial de desenvolvimento urbano sustentável.

Segundo a Cepal (2000, p. 1), na América Latina e no Caribe, principalmente na década de 1990, consolidou-se

[...] la tendencia a la desaceleración del ritmo de crecimiento de la población urbana, al bajar su crecimiento vegetativo debido a la transición demográfica que se vive y al reducirse la migración desde el campo. [...) Otro cambio se refiere a la migración del campo a la ciudad, que ya no es la forma predominante de desplazamiento poblacional. Ahora prima la interurbana: entre los distintos estados, entre ciudades, a otros países. Situaciones de violencia, como las que sufre Colombia o la que afectó a Guatemala, generan un desplazamiento de grandes masas de población rural o semi rural. En Colombia, cifras no oficiales estiman en alrededor de un millón a los desplazados.

Com isso, a característica negativa das atuais cidades latinas americanas e do Caribe é a segregação, ou seja, os ricos se isolam em bairros ou cidades afastadas do centro urbano principal, visando à qualidade de vida e a tranquilidade. Por sua vez, os pobres vivem em áreas de riscos com precárias condições de moradias, 
normalmente longe do seu local de trabalho. O que se observa nesses estudos que comparam os países da América Latina é o que Schapira (1999) apresenta em seu texto, ou seja, há tendências no processo de urbanização desses países que são comuns, apesar de se tratar de diferentes nações. Tendências essas que podemos descrever como: formas ilegais de ocupação; renuncia do estado às questões sociais e de gerenciamento urbano; e, a segregação socioespacial. Outras características negativas colocadas pela Cepal (2000, p. 1) foram que

[...] se han debilitado los mecanismos tradicionales de integración como la enseñanza pública, los sistemas de salud pública o, incluso, los lugares centrales de recreación y cultura. La informalidad habitacional ha aumentado en algunas ciudades sudamericanas. En Lima, más del $40 \%$ vive ahora en asentamientos ilegales; en Quito es el 50\%. En Venezuela, el $48 \%$ de la superficie construida en Maracaibo corresponde a inmuebles asentados ilegalmente. En Rio de Janeiro y Belo Horizonte, la población “favelada" es de 20\%, en São Paulo, de $22 \%$ y en Recife, de $46 \%$. La propiedad de la vivienda en el Caribe, en cambio, es alta: entre el $60 \%$ y $80 \%$.

Para Santos (1994) o processo de modernização capitalista e de desenvolvimento do interior dos países explicava o comportamento estrutural das grandes cidades, sobretudo a pobreza que faz parte dessa região latina. Para o autor, é na metrópole que encontramos, ao mesmo tempo, a modernização das atividades econômicas e uma expansão da pobreza. Esse fenômeno de modernização e pobreza num mesmo espaço geográfico, passou a ser chamado por Santos de "involução metropolitana" ${ }^{2}$. Dessa forma, o que está ocorrendo, no período contemporâneo, é um processo de desconcentração industrial seguido de uma descentralização das atividades produtivas e que devido às facilidades dos meios de comunicação e transporte, as empresas estão se interiorizando. Procuram se instalar longe das grandes aglomerações, visando, principalmente, a isenção de impostos e acesso à mão de obra qualificada e, de preferência, que não estejam ligadas às forças sindicais (STAMM et al., 2004). Dessa maneira, as cidades de porte médio e pequenas do interior estão crescendo proporcionalmente mais que as metrópoles, fato que pode ser relacionado indiretamente com a involução metropolitana do país (STAMM, 2013).

Segundo Maricato (2001, p. 16), “o Brasil, como os demais países da América Latina, apresentou intenso processo de urbanização, especialmente na segunda metade do século XX", havendo uma forte contribuição das migrações internas nos anos 1980. Os deslocamentos intra e interestaduais e intra-regionais colaboraram para a consolidação das transformações e tendências populacionais no interior dos estados e da mudança da urbanização nacional como um todo, visto que nos anos 
1960, esses deslocamentos foram caracterizados pelo esvaziamento populacional do interior em direção as metrópoles, principalmente para o eixo Rio-São Paulo (Santos, 2005). A evolução desse processo de urbanização pode ser visualizada na Tabela 1, que mostra também a população total e a divisão da população urbana e rural do país.

Tabela 1 - Evolução da população e do índice de urbanização no Brasil (1940-2010)

\begin{tabular}{c|c|c|c|c}
\hline Ano & População Total & População Urbana & População Rural & Urbanização (\%) \\
\hline 1940 & 41.236 .315 & 12.880 .182 & 28.356 .133 & 31,24 \\
1950 & 51.944 .397 & 18.782 .891 & 33.161 .506 & 36,16 \\
1960 & 70.070 .457 & 31.303 .034 & 38.767 .423 & 44,67 \\
1970 & 93.139 .037 & 52.084 .984 & 41.054 .053 & 55,92 \\
1980 & 119.002 .706 & 80.436 .409 & 38.566 .297 & 67,59 \\
1991 & 146.825 .475 & 110.990 .990 & 35.834 .485 & 75,59 \\
2000 & 169.799 .170 & 137.953 .959 & 31.845 .211 & 81,25 \\
2010 & 190.755 .799 & 160.925 .792 & 29.830 .007 & 84,36 \\
\hline
\end{tabular}

Fonte: Elaborado pelos autores a partir de IBGE (2003 e 2010).

Apesar do aumento considerável da população total (362\%) entre 1940-2010, é interessante observar que o aumento da população urbana foi de $1.149 \%$. Enquanto isso, a população rural cresceu apenas $5,20 \%$, refletindo na conhecida evolução da urbanização brasileira que passou de 31,24\%, em 1940, para 84,36\% em 2010. Embora a população rural tenha perdido, por meio do êxodo rural, cerca de 11 milhões de pessoas entre 1970 (período em que atingiu a maior população rural) e 2010, acredita-se que a alta taxa de natalidade também contribuiu para o crescimento da população urbana.

A Tabela 2 mostra a evolução das metrópoles em termos de população no total nacional, em que se observa uma diminuição do ritmo de crescimento das Regiões Metropolitanas (RMs) no Brasil. Vale ressaltar que esse crescimento populacional das metrópoles trouxe também problemas correlatos, como, a falta de crescimento da capacidade de absorção dessas cidades, traduzindo num rápido aumento das favelas (PERLMAN, 1977). A autora ainda enfatiza que possivelmente nenhuma das grandes cidades, nos países em desenvolvimento, esteja conseguindo o necessário incremento em termos de novas oportunidades de trabalho, serviços urbanos, infra-estrutura, acomodações e capacidade administrativa, que permita absorver o atual crescimento demográfico.

No início dos anos 1990, Santos (2005, p. 11) analisou o processo de urbanização brasileira e destacou que: 
Ao longo do século [...] o processo brasileiro de urbanização revela uma crescente associação com a pobreza, cujo locus passa a ser, cada vez mais, a cidade, sobretudo a grande cidade. O campo brasileiro moderno repele os pobres, e os trabalhadores da agricultura capitalizada vivem cada vez mais nos espaços urbanos. A indústria se desenvolve com a criação de pequeno número de empregados, e o terciário associa formas modernas a formas primitivas que remuneram mal e não garantem a ocupação.

A urbanização nas grandes cidades passou de forma indireta a fazer parte de uma construção de cidades, de forma ilegal, ou seja, sem a participação dos governos, ajuda financeira ou pessoal, pois não estavam aptos para fazer o planejamento (MARICATO, 2001). Para Perlman e também para Maricato, esse processo levou ao aumento considerável de favelas, no Brasil, habitadas por milhares de pessoas descapitalizadas, na maior parte sem acesso a educação e sem as mínimas condições sanitárias básicas e, principalmente, ainda fora do mercado de trabalho formal. Dessa forma, Maricato (2001, p. 39) sintetizou o processo de urbanização e enfatizou que o mesmo "se apresenta com uma máquina de produzir favelas e agredir o meio ambiente" e, complementando, Schapira (1999, p. 131) afirma que "hoje a pobreza domina a questão urbana".

Assim, a urbanização se tornou mais veloz que o processo da industrialização e a criação de instituições urbanas compatíveis, indicando um gap entre os fenômenos, o que acabou gerando a "superurbanização" ou a "hiperurbanização". Nessa mesma linha, Davis (2006) contribui e afirma que a superurbanização estaria vinculada à reprodução da pobreza e não pela oferta de emprego, uma vez que o estereótipo clássico do uso intensivo de mão de obra no campo e o uso intensivo do capital na metrópole industrial estão invertidos na maioria dos países em desenvolvimento. 
Tabela 2 - População residente nas Regiões Metropolitanas no Brasil - 1970 a 2010*

\begin{tabular}{l|r|r|r|r|r}
\hline \multirow{2}{*}{ Regiões metropolitanas } & \multicolumn{5}{|c}{ População residente } \\
\cline { 2 - 6 } & \multicolumn{1}{|c|}{1970} & \multicolumn{1}{c}{1980} & \multicolumn{1}{c}{1991} & \multicolumn{1}{c}{2000} & \multicolumn{1}{c}{2010} \\
\hline Belém & \multicolumn{1}{|c|}{656.351} & 1.000 .349 & 1.401 .305 & 1.794 .981 & 2.101 .883 \\
Fortaleza & 1.038 .041 & 1.581 .588 & 2.401 .878 & 2.975 .703 & 3.615 .767 \\
Recife & 1.792 .688 & 2.348 .362 & 2.919 .979 & 3.335 .704 & 3.690 .547 \\
Salvador & 1.148 .828 & 1.772 .018 & 2.496 .521 & 3.018 .285 & 3.573 .973 \\
Belo Horizonte & 1.605 .663 & 2.541 .788 & 3.515 .542 & 4.342 .367 & 5.414 .701 \\
Rio de Janeiro & 7.082 .404 & 9.018 .637 & 9.814 .574 & 10.872 .768 & 11.835 .708 \\
São Paulo & 8.137 .401 & 12.588 .439 & 15.444 .941 & 17.834 .664 & 19.683 .975 \\
Curitiba & 820.766 & 1.441 .743 & 2.063 .654 & 2.725 .629 & 3.174 .201 \\
Porto Alegre & 1.531 .168 & 2.232 .370 & 3.147 .010 & 3.655 .834 & 3.958 .985 \\
\hline Total RMs & 23.813 .310 & 34.525 .294 & 43.205 .404 & 50.555 .935 & 57.049 .740 \\
Total Brasil & 93.139 .037 & 119.002 .706 & 146.825 .475 & 169.282 .561 & 190.755 .799 \\
\hline \% RMs/Brasil & 25,57 & 29,01 & 29,43 & 29,86 & 29,91 \\
\hline \% Crescim. RMs ${ }^{* *}$ & - & 44,98 & 25,14 & 17,01 & 12,84 \\
\hline \% Crescim. Brasi ${ }^{* *}$ & - & 27,77 & 20,86 & 15,64 & 12,34 \\
\hline
\end{tabular}

Fonte: Elaborado pelos autores a partir de IBGE (2003 e 2010).

*Nessa tabela são apresentadas apenas as primeiras metrópoles institucionalizadas na década de 1970.

** Percentual de crescimento populacional das Regiões Metropolitanas e do Brasil entre os decênios.

Nessa Tabela 2, fica evidenciada a estagnação relativa da participação das populações residentes nas RMs no total nacional em torno de $29 \%$, entre 1980 e 2010 esse percentual não chegou a subir 1\%, porém, quando se verifica o percentual de crescimento entre as décadas analisadas, é observada uma redução, apesar de ainda manterem um crescimento superior ao nacional, por serem regiões que foram afetadas pelas trocas estruturais na economia brasileira nas últimas décadas. Com isso, a principal tendência do processo de urbanização no Brasil é uma menor participação das regiões metropolitanas na população do país. Por isso, ocorre o fenômeno de "desmetropolização", fator indutor da difusão de atividades mais modernas por todo território nacional e, consequentemente, uma maior distribuição da população no sistema urbano brasileiro - elementos esses que nos fazem compreender a tendência da "desmetropolização". Santos (1994) afirmou que esse processo de transformação do espaço, pelo qual o Brasil passou na década de 1980 e início de 1990, foi um fenômeno paralelo de metropolização e desmetropolização. Por outro viés, verifica-se também um dinamismo socioespacial nas aglomerações urbanas formadas no entorno de cidades de porte médio e, segundo Soares (2005), com as economias dos núcleos metropolitanos cada vez mais vinculadas às 
atividades terciárias e de gestão, as cidades de porte médio emergem no cenário nacional com o papel de centros industriais e de atração das migrações internas.

No caso dos dois centros principais - São Paulo e Rio de Janeiro - vale ressaltar que a infraestrutura básica existente nessas cidades, as quais estavam ligadas ao comércio internacional, permitiu a localização das indústrias nesses dois principais pólos brasileiros e em suas áreas mais próximas, explicando a concentração das atividades econômicas nesses dois centros primazes. Porém, a partir da década de 1970, houve um processo de desconcentração econômica e industrial, fato que ocorreu principalmente na Região Metropolitana de São Paulo (RMSP). Segundo Diniz (1993) e Andrade e Serra (2001a), este processo foi composto de duas fases: na primeira ocorreu uma relativa dispersão da produção industrial no País como um todo; e na segunda fase, ocorreu uma relativa reconcentração da atividade industrial dentro de um polígono (chamado de polígono industrial brasileiro), delimitado pelos seus vértices as regiões de: Belo Horizonte (MG); Uberlândia (MG); Maringá (PR); Porto Alegre (RS); Florianópolis (SC) e São José dos Campos (SP) (Figura 1).

Tendo em vista o crescimento significativo nos últimos anos da indústria petrolífera, tais apontamentos sobre a concentração do desenvolvimento industrial brasileiro podem ser repensados de modo a incluir o Estado do Rio de Janeiro. Dessa forma, a possibilidade de um novo polígono é apresentada por meio da delimitação dos vértices: as regiões de Belo Horizonte (MG), Uberlândia (MG), Maringá (PR), Porto Alegre (RS), Florianópolis (SC) e Campos de Goytacazes (RJ) ${ }^{3}$, conforme o Figura 2. 

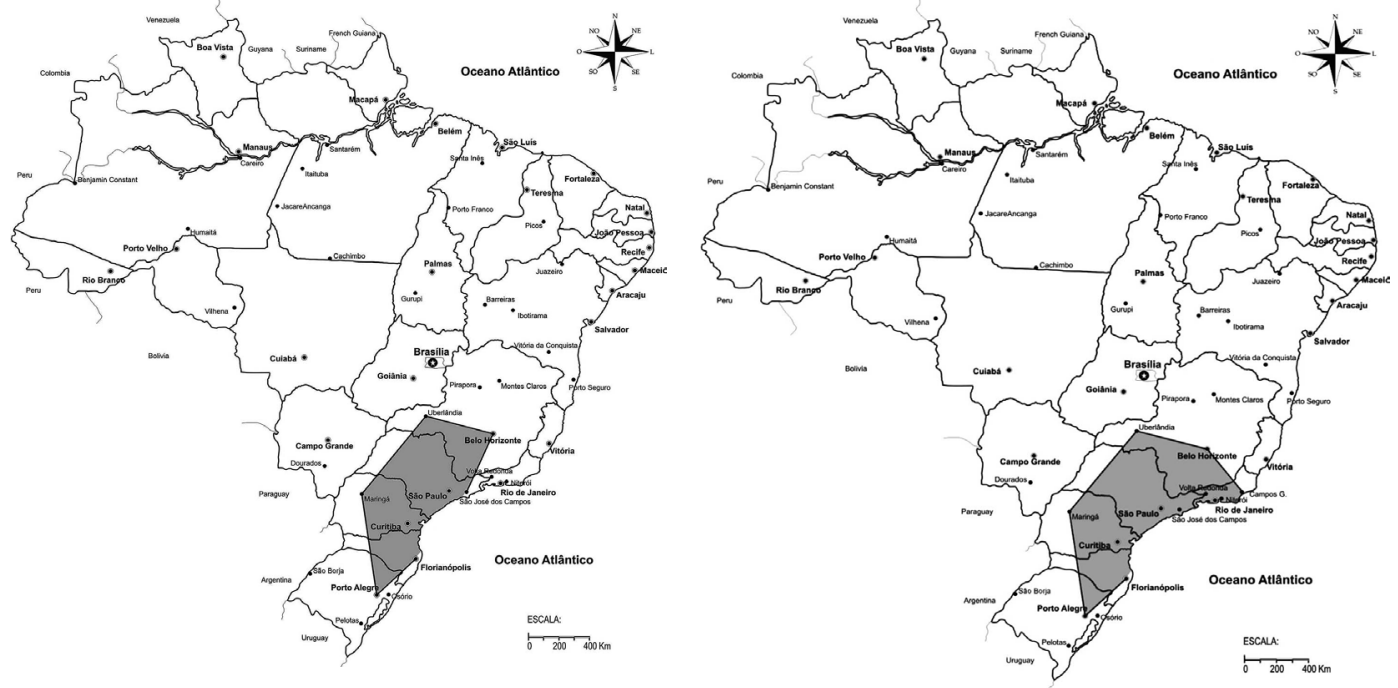

Fonte: Elaborado pelo autor a partir de Andrade e Serra (2001a, Fonte: Adaptado pelos autores a partir de Andrade e Serra p. 346).

Malha regional digital do Brasil - IBGE (1997). (2001a, p.346).

Bernardes (2003) acrescentou múltiplos elementos que podem levar ao processo de desconcentração e, consequentemente, ao crescimento da urbanização nacional. Entre eles, enfatizam-se as dispersões da indústria e a modernização do campo, a proximidade das indústrias agrícolas e as novas formas de consumo material e de consumo imaterial que, mesmo sendo um fenômeno geral, teve particular expressão em áreas mais desenvolvidas do país. Santos (1994) diz que, no período de 1980, enquanto os indicadores macroeconômicos indicaram uma crise no país, algumas regiões do interior mostraram uma tendência inversa, sustentando o crescimento. É exemplo o caso do Estado de São Paulo, “onde a participação do interior na formação da riqueza não para de crescer, ao passo que a da metrópole está em baixa" (SANTOS, 1994, p. 57).

É possível fazer uma analogia com outros países por meio dos estudos de Davis (2006) o qual fez um relato de algumas das megacidades de países em desenvolvimento enfatizando, nesse caso, que na China 43\% da população em 1993 era urbana e que o número absoluto de cidades aumentou mais de $200 \%$ desde 1978 , mas que as grandes metrópoles, apesar do crescimento nesse período, assim como 0 ocorrido no Brasil - conforme já apresentado na Tabela 2 - também reduziram sua 
participação relativa no total da população urbana do país. "Em vez disso, foram as cidades pequenas e médias e as vilas recentemente 'providas' a cidades que absorveram a maior parte da força de trabalho rural tornada excedente pelas reformas de mercado a partir de 1979" (DAVIS, p. 18). Da mesma forma, alguns dados, conforme Gráfico 1, confirmam a tendência do "surgimento" e respectivo aumento das cidades de porte médio no Brasil.

Gráfico 1 - Distribuição da população urbana segundo sua classe de tamanho - 1940 a 2010

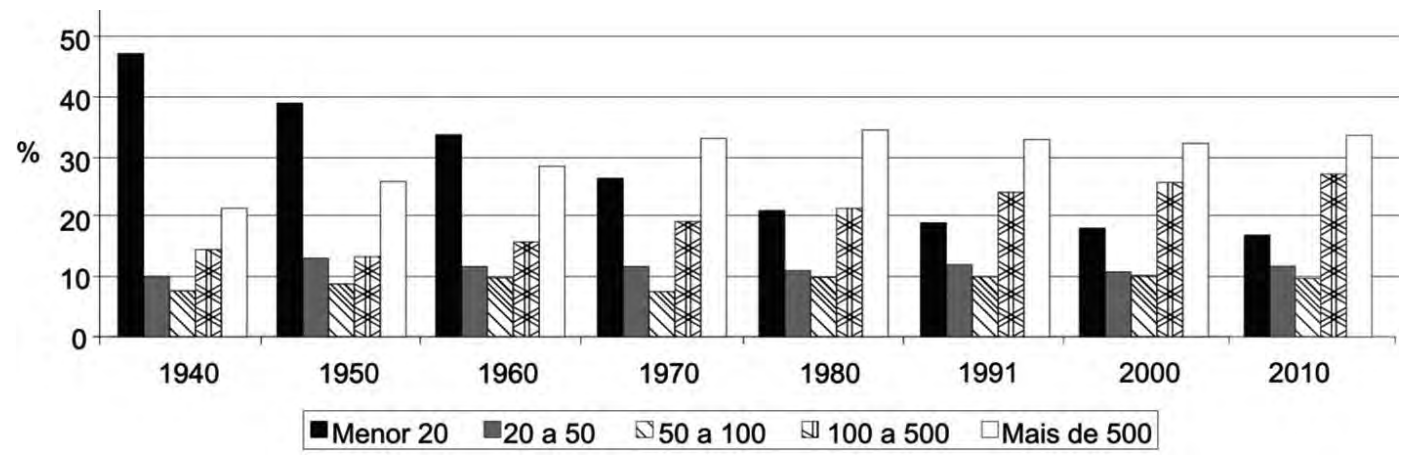

Fonte: Adaptado pelos autores a partir de Brito, Horta e Amaral (2001) e IBGE (2010).

No contexto geral, entre 1940 e 2010, o número total de municípios no país aumentou consideravelmente, passando de 1.574 para 5.565 um incremento de 3.991 municípios. Os municípios com população urbana inferior a 20 mil habitantes passaram de 857 para 4.471. Apesar desse aumento (421,7\%), pode-se observar no Gráfico 1 que os municípios com menos de 20 mil habitantes em 1940 abrigavam quase 50\% da população urbana no país, e em 2010 o total da população urbana nessas cidades era um pouco maior do que $17 \%$.

Apesar das pequenas oscilações das cidades com 20 mil a 50 mil e as com 50 mil a 100 mil habitantes cresceram num percentual bem pequeno, apresentando, ao longo do período, participações relativas praticamente constantes. Assim, as cidades de aptidão exclusivamente rural e com baixa densidade demográfica perderam importância na localização do conjunto da população urbana para as cidades de porte médio. As cidades entre 20 mil e 50 mil habitantes mantiveram a sua posição ao longo do tempo.

Os municípios enquadrados como cidades de porte médio aumentaram consideravelmente sua participação na população total do país; ou seja, o que era representado em 1940 por cerca de 15\% da população urbana do país, em 2010 chegou a abrigar pouco mais de $27 \%$ dessa população. Segundo Andrade e Serra (2001b) é 
a partir do desenvolvimento brasileiro, da década de 1970, que as cidades de porte médio surgem como alternativa de difusão do desenvolvimento econômico no país.

As cidades com mais de 100 mil habitantes aumentaram consideravelmente sua participação no total dos municípios brasileiros. Todavia, pelo crescimento acelerado das cidades de porte médio, nota-se que há continuidade da metropolização no Brasil. A explicação desse fenômeno é que as cidades com população acima de 500 mil habitantes cresceram até 1980 e desde então os dados do Gráfico 1 mostram uma relativa estagnação acompanhada por queda percentual na participação total da população.

\section{Cidades de porte médio no Brasil e a distribuição da população}

Esse processo acelerado de urbanização que vem ocorrendo no Brasil nos últimos anos vem imprimindo marcas importantes no processo de distribuição espacial da população nacional (Baeninger, 2000). Para a autora, esse acelerado processo contribuiu para a concentração metropolitana e, ao mesmo tempo, para a expansão da rede urbana, com o crescimento dos centros e sub-centros regionais além do crescimento de população urbana em cidades de diferentes tamanhos. Com a análise dos dados expostos no item anterior, ficam evidentes duas situações no Brasil: a) a evolução das cidades de porte médio no entorno ou com influência das metrópoles e capitais estaduais; e b) o crescimento e desenvolvimento de cidades interioranas de porte médio, em áreas não metropolitanas.

Essa situação traz três explicações plausíveis: o papel indutor da desconcentração industrial iniciada na década de 1970; a expansão da fronteira agrícola; e as deseconomias de aglomeração dos grandes centros urbanos (conforme Tabela 3). 
Tabela 3 - Distribuição da população urbana segundo sua classe de tamanho - 1970 a 2010

\begin{tabular}{|c|c|c|c|c|c|}
\hline \multirow{2}{*}{ Cidades } & \multicolumn{5}{|c|}{ População urbana total (\%) } \\
\hline & 1970 & 1980 & 1991 & 2000 & 2010 \\
\hline \multicolumn{6}{|c|}{ Cidades não metropolitanas } \\
\hline$<20.000$ & 25,82 & 20,92 & 19,07 & 18,57 & 16,57 \\
\hline $20.000 a<50.000$ & 9,48 & 9,91 & 11,29 & 10,60 & 10,62 \\
\hline $50.000 a<100.000$ & 5,77 & 7,40 & 8,07 & 8,28 & 8,02 \\
\hline $100.000 a<500.000$ & 10,29 & 14,84 & 16,41 & 17,31 & 16,62 \\
\hline Mais de 500.000 & 0,00 & 0,00 & 2,23 & 4,25 & 6,87 \\
\hline Total não Metropolitanas & 51,36 & 53,07 & 57,07 & 59,02 & 58,70 \\
\hline \multicolumn{6}{|c|}{ Cidades metropolitanas } \\
\hline$<20.000$ & 1,09 & 0,43 & 0,27 & 0,28 & 0,55 \\
\hline $20.000 a<50.000$ & 2,56 & 1,49 & 1,15 & 0,87 & 1,22 \\
\hline $50.000 a<100.000$ & 2,03 & 3,10 & 2,16 & 2,30 & 1,91 \\
\hline $100.000 a<500.000$ & 7,47 & 6,62 & 8,02 & 8,78 & 10,71 \\
\hline Mais de 500.000 & 1,40 & 4,19 & 4,76 & 4,91 & 4,47 \\
\hline Total Metropolitanas (sem Núcleos) & 14,55 & 15,83 & 16,36 & 17,15 & 18,35 \\
\hline Núcleos Metropolitanos & 34,09 & 31,11 & 26,56 & 23,83 & 22,95 \\
\hline Total Metropolitanas & 48,64 & 46,93 & 42,93 & 40,98 & 41,30 \\
\hline Total da Pop. Urbana & 52.084 .984 & 80.436 .409 & 110.990 .990 & 137.697 .439 & 160.925 .792 \\
\hline
\end{tabular}

Fonte: Censos Demográficos de 1970, 1980, 1991, 2000 e 2010 - Adaptada de Brito, Horta e Amaral (2001).

Os resultados dessas duas situações (cidades não metropolitanas e metropolitanas) demonstram que até o início da década de 1980, com a "explosão" da população urbana, caminhava-se na direção de uma concentração nas grandes cidades, com destaque para aquelas cidades com mais de 500 mil habitantes, apresentando uma relativa estabilização nos períodos posteriores. No decênio de 1980, as cidades de porte médio não-metropolitanas iniciam um ciclo de expansão. Elas apresentam uma nova dinâmica em relação às cidades de maior porte, revertendo esse processo de crescimento, ou seja, as cidades de porte médio cresceram mais intensamente que as cidades com mais de 500 mil habitantes.

A participação das cidades de porte médio não metropolitanas, ao longo do período, cresceu significativamente no total da população brasileira de 10,29\%, em 1970, para 16,62\%, em 2010. Esses números não são acompanhados pelas cidades de porte médio localizadas em regiões metropolitanas, que cresceram apenas 3,24 pontos percentuais, no período, em 1970 representavam 7,47\%, e passou em 2010, para $10,71 \%$. As cidades de maior porte populacional também apresentaram o mesmo crescimento, apesar do rápido crescimento até a década de 1970.

As atuais cidades de porte médio não metropolitanas exerceram grande atração de fluxos migratórios e algumas delas atingiram e/ou irão atingir um estágio 
sub-metropolitano cuja dimensão varia segundo as dinâmicas de cada região brasileira. Nessa perspectiva de crescimento, as cidades de porte médio não só cumpriram o papel de contenção dos fluxos migratórios, que se dirigiam para os grandes centros em períodos anteriores, mas também representam a dispersão da população nacional, sendo que a mesma está relacionada à desconcentração industrial e à mobilidade da fronteira agrícola e, de forma indireta, com a não contribuição do aumento da pobreza, da violência e de segregação urbana em áreas já consolidadas.

A Tabela 4 apresenta dados referentes ao número absoluto de municípios por classe de tamanho e a percentagem de sua respectiva população total.

Tabela 4 - Classificação dos municípios segundo sua classe de tamanho - 1970 a 2010

\begin{tabular}{|c|c|c|c|c|c|c|c|c|c|c|}
\hline \multirow{2}{*}{$\begin{array}{l}\text { Classe de tamanho dos } \\
\text { municípios (mil habitantes) }\end{array}$} & \multicolumn{2}{|c|}{1970} & \multicolumn{2}{|c|}{1980} & \multicolumn{2}{|c|}{1991} & \multicolumn{2}{|c|}{2000} & \multicolumn{2}{|c|}{2010} \\
\hline & mun. & $\%$ & mun. & $\%$ & mun. & $\%$ & mun. & $\%$ & mun. & $\%$ \\
\hline$<20$ & 2.875 & 28,1 & 2.758 & 21,3 & 3.095 & 19,6 & 4.022 & 19,8 & 3914 & 17,1 \\
\hline Entre $>20$ e $<50$ & 828 & 26,4 & 859 & 22,1 & 930 & 19,2 & 958 & 16,9 & 1043 & 16,4 \\
\hline Entre $>50$ e $<100$ & 158 & 11,0 & 236 & 13,1 & 281 & 13,1 & 303 & 12,4 & 325 & 11,7 \\
\hline Entre $>100$ e $<500$ & 80 & 15,5 & 120 & 19,1 & 160 & 21,7 & 193 & 23,3 & 245 & 25,5 \\
\hline Mais de $>500$ mil & 11 & 19,0 & 18 & 24,4 & 25 & 26,5 & 31 & 27,6 & 38 & 29,3 \\
\hline Total Brasil & 3.952 & 100 & 3.991 & 100 & 4.491 & 100 & 5.507 & 100 & 5565 & 100 \\
\hline
\end{tabular}

Fonte: Elaborada pelo autor a partir de IBGE/Censo Demográfico de 1970, 1980, 1991, 2000 e 2010.

Nota: Mun. - Número absoluto de municípios

$\% \quad-\%$ na população total.

Apesar da emancipação de 1.613 municípios entre 1970 e 2010 (que correspondeu a um aumento de $40,8 \%$ no total de municípios no país), observa-se um incremento de $36,14 \%$ no total de municípios de pequeno porte, de até 20 mil habitantes, mesmo com uma diminuição na participação da população no total desses municípios de 28,1\% em 1970, para 17,1\% em 2010. Para os municípios da segunda faixa houve um aumento de 215 municípios no período, mas a participação da população total, assim como o anterior, diminuiu cerca de $10 \%$ (de $26,4 \%$ para $16,4 \%$ ).

Cabe destacar o aumento dos municípios com população acima de 100 mil habitantes que, em 1970, representavam 2,3\% do total de municípios no Brasil, com cerca de 34,5\% da população nacional e que, em 2010, já eram 5,09\% do total de municípios brasileiros, o que representavam $54,7 \%$ da população total.

As Figuras 3 e 4 expressam a dispersão das cidades de porte médio no Brasil para os períodos de 1970 e 2010 respectivamente. Essas figuras apresentam apenas as cidades de porte médio no período, aquelas cidades cuja população urbana apresentava-se entre $100 \mathrm{mil}$ e 500 mil habitantes. Observa-se que algumas cidades da Figura 3, em 1970, não aparecem na Figura 4, em 2010. Isso se deve, 
basicamente, a três fatores: a) algumas cidades apresentaram um forte poder de atração populacional fazendo com que tais cidades ultrapassassem o limite superior de 500 mil habitantes; b) as cidades essencialmente agrícolas e que na década de 1970 ocupavam muita mão-de-obra, e essas por sua vez, perderam população devido ao êxodo rural, ficando assim abaixo dos 100 mil habitantes; e, c) por serem cidades com grandes proporções territoriais e possuírem vários distritos administrativos, que por sua vez pode ter ocorrido seu desmembramento (emancipação) em outras cidades, pois como já visto nesse período houve um aumento no número de municípios no Brasil.

Comparando as Figuras 3 e 4, observa-se o perfil da dispersão das cidades de porte médio pelo Brasil. Em 1970 havia um aglomerado de cidades de porte médio basicamente formado pelas regiões Sul e Sudeste. As duas regiões representavam $71,25 \%$ do total das cidades de porte médio do Brasil que, na época, somavam um total de 80 municípios. No ano de 2010, o percentual das regiões, Sul e Sudeste, diminuiu para $67,76 \%$, um indício da dispersão ou do crescimento da população em outras regiões do Brasil, que atualmente somam um total de 245 municípios.

Figura 3 - Dispersão das cidades de porte médio no Brasil - 1970

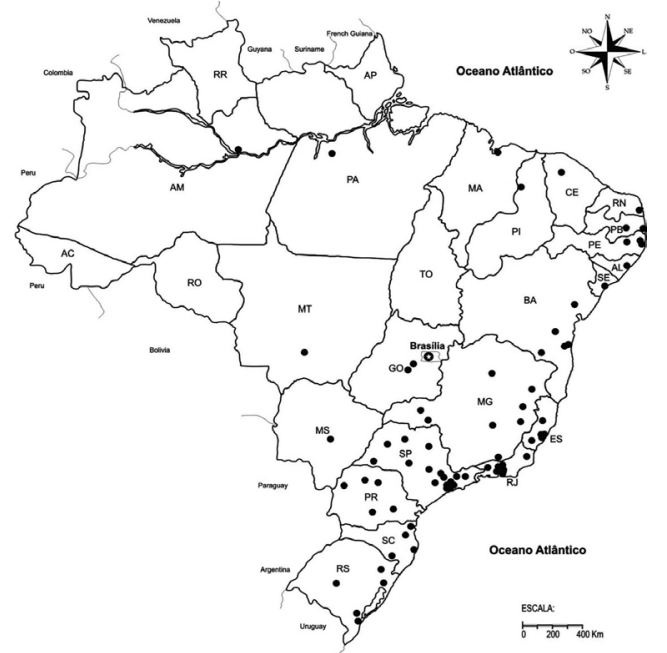

Figura 4 - Dispersão das cidades de porte médio no Brasil - 2010

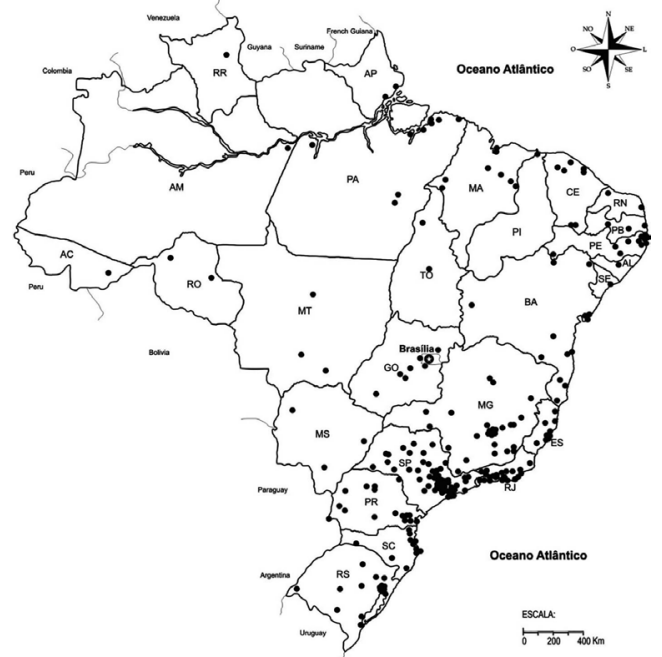

Fonte: Elaborado pelos autores a partir dos dados do IBGE, Censo Demográfico (1970 e 2010 ) - Malha municipal digital do Brasil de 1997. 
Pela dispersão espacial das cidades nota-se que a difusão se dá no sentido leste $\rightarrow$ oeste do país, tornando as cidades de porte médio em plataformas de bens e serviços para as cidades locais e sub-regionais do Centro-Oeste e Norte do Brasil, tanto que a fronteira agrícola se esgota na região Sul do Brasil no início dos anos 1980 e entre 1980 e 2010 ela amplia tanto no número de cidades de porte médio (passando de 20 para 44) quanto na participação da população residente (passando de 3.305.869 habitantes em 1980 para 8.634.378 habitantes em 2010). Verifica-se que o movimento expansivo do crescimento da população ao longo do território, depois da ocupação das terras itinerantes, fez com que o processo de crescimento populacional se tornasse intensivo e percolativo ${ }^{4}$, marcando apenas algumas cidades. O mesmo processo ocorre no Centro-Oeste e no Norte do Brasil. A comparação das Figuras 3 e 4, ainda mostra que o processo de dispersão da população de forma expansiva continua marcante nas regiões do Cerrado e da Amazônia.

Provavelmente, dentro de mais 20 anos, com a ocupação completa da fronteira agrícola nessas áreas, o processo se reverterá de forma mais intensiva e também percolativa. Essa constatação é confirmada por Santos (1994) e Silveira (2003) ao afirmarem que as cidades de porte médio estão ligadas a formas modernas de produção e consumo estimuladas pela renda da agricultura moderna e um parque industrial associado ao setor primário. Alguns dados atualizados pelo IBGE (2011) confirmam que os municípios menos populosos tiveram baixas taxas de crescimento no período 2000-2011 (Figura 5).

Figura 5 - Taxa geométrica de crescimento anual (\%), segundo as classes de tamanho dos municípios (número de habitantes entre 2000-2011)

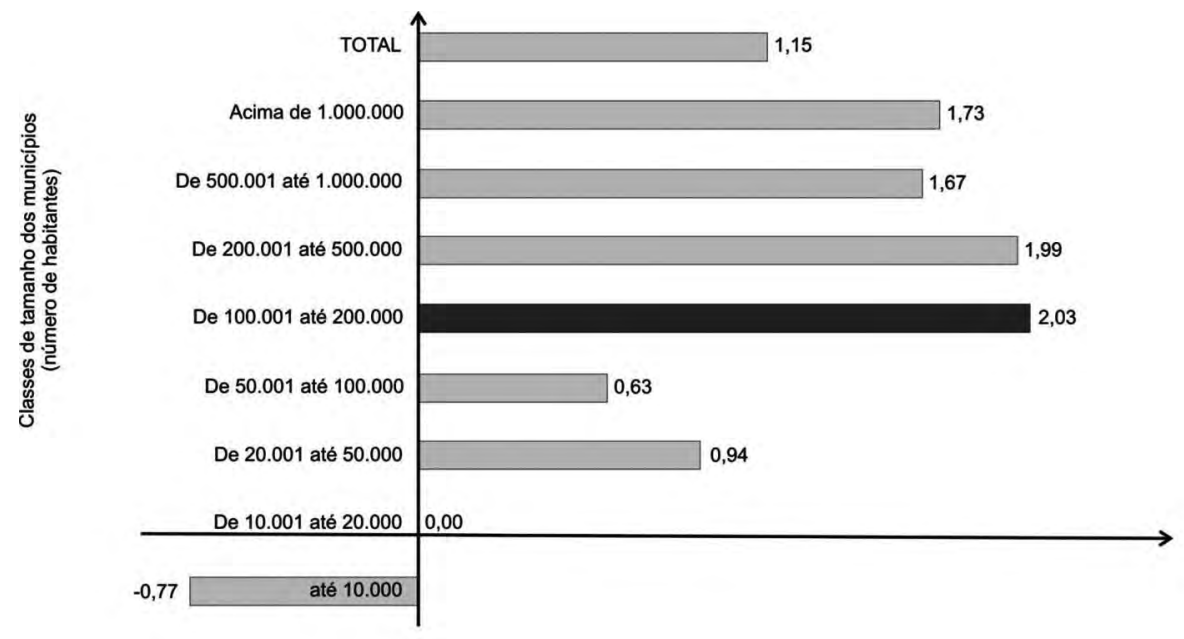

Fonte: IBGE (2011).

Taxas de Crescimento (\%) 
Para o IBGE (2011), as significativas taxas de crescimento dos grandes municípios em volume populacional (acima de 500 mil habitantes) foram influenciadas "pelo componente vegetativo e por um saldo migratório que prevalece favorável à imigração, embora possam estar experimentando reduções no transcurso das últimas quatro décadas". Como afirmado por Santos (1994) e Silveira (2003), acima, e confirmado pelo IBGE (2011) na Figura 5, os municípios de porte médio (aqueles entre 100 e 500 mil habitantes) protagonizaram os crescimentos demográficos mais expressivos nos últimos anos, destacando-se aqueles cujas economias estão voltadas ao agronegócio, às atividades petrolíferas e os que demandam mão de obra para a construção civil.

\section{Considerações finais}

O objetivo deste artigo foi analisar a dispersão da população urbana e a difusão das cidades de porte médio no Brasil. Observou-se uma grande evolução das cidades de porte médio não-metropolitanas, que apresentaram índices elevados na participação da população total do Brasil. Já as cidades de porte médio metropolitanas cresceram, mas não tão expressivamente. As cidades de porte médio apresentam condições de se adaptar às novas exigências indispensáveis aos novos modos de produção.

A recente emergência dessas cidades no cenário nacional cria condições de implementar projetos de planejamento urbanos para que não ocorram ou minimize os problemas causados pela urbanização, que na história recente causaram e ainda causam problemas de difícil solução nas grandes aglomerações populacionais, tais como o aumento da violência, da pobreza e da segregação social. Schapira (1999, p. 131) deixa evidências da falta de políticas de contenção populacional para os grandes centros urbanos, uma vez que a autora afirma que "durante os anos de 1960, a teoria da marginalidade se certificava que as previsões otimistas sobre a integração dos migrantes no setor industrial não tinha sido concluídas, que as periferias urbanas continuavam a aumentar e que os habitantes não acessavam ao proletariado industrial".

No entanto, através do aumento do número de cidades de porte médio no Brasil ocorreu um processo de desconcentração populacional das grandes metrópoles nacionais (São Paulo, Rio de Janeiro, Porto Alegre, Recife, Salvador, Belo Horizonte e Fortaleza), processo esse que se intensificou a partir dos anos 1980. Assim, as cidades de porte médio serviram, em grande parte do seu período de crescimento, como "diques" de contenção dos fluxos migratórios dos grandes centros urbanos, 
bem como estão induzido principalmente à difusão de atividades mais modernas por todo território nacional e, consequentemente, uma maior distribuição da população no sistema urbano brasileiro.

Por fim, cabe salientar que os grandes responsáveis pela dispersão espacial da população foram a tendência à desconcentração industrial, ocorrida entre 1970 e 1990; a mobilidade da fronteira agrícola, estimulada pela modernização da agricultura e a transferência de excedentes populacionais das zonas rurais; e os investimentos em infra-estrutura, que integraram o interior do Brasil à dinâmica da economia nacional. Nesse sentido, a difusão espacial das cidades de porte médio foi uma consequência do perfil do desenvolvimento econômico brasileiro e sua urbanização. O resultado final foi o adensamento das cidades de porte médio litorâneas e a percolação das cidades de porte médio localizadas no interior do Brasil, em particular aquelas nas áreas limítrofes à fronteira agrícola.

Assim, a difusão espacial da urbanização brasileira no final do século XX é marcada por um processo expansivo, ligado à mobilidade das terras a serem ocupadas pela agricultura itinerante; e um processo intensivo, marcado pela ocupação definitiva das áreas produtivas. Traçando-se um comparativo com o desenvolvimento da agropecuária no Brasil, a modernização da agropecuária foi útil na liberação de mão de obra para ocupar os fronts pioneiros. Essa ocupação criou novos mercados em regiões consideradas "vazias" e de baixa densidade demográfica nos anos 1970. Isso demonstra o quanto a dinâmica populacional brasileira é dependente da dinâmica dos espaços rurais, da forma como ocupa a força de trabalho e do perfil da demanda bens e serviços das áreas urbanas. Enquanto isso, as metrópoles nacionais e regionais apresentam um continuum urbano-industrial e parte das cidades de porte médio localizadas nas áreas de ocupação recente será marcada por um continuum urbano-rural. Ao longo do século XXI, o perfil produtivo dessas cidades mudará marcando a industrialização e a formação de mercados expressivos no interior do país. Para que isso se confirme, a economia brasileira deverá garantir a estabilidade dos preços, a conquista de novos mercados para o agronegócio brasileiro e a abertura de postos de trabalho no interior do país, reduzindo as desigualdades sociais e a pobreza, principalmente nos grandes centros urbanos. 


\title{
Brazilian population distribution in the focus of mid-sized cities
}

\begin{abstract}
The industrial dispersal, the mobility of the agricultural border, and infrastructure investments that integrated the interior of Brazil to the dynamics of the national economy are responsible for the spatial dispersion of Brazilian population. This paper shows the evolution of the medium-sized cities in Brazil from 1970 to 2010 from a population-based approach. The methodology is characterized by documentary research. Throughout the study it is observed that the medium-sized cities have a potential strategic position for the continuity of the regional dispersal in Brazil. The results show that the medium-sized cities increased their share in the total population of the country, which in 1970 was represented by about $18 \%$ of the urban population in 2010 came to house just over $27 \%$ of this population.
\end{abstract}

Key words: Urban population; Medium-sized cities; Urban system, Brazil.

\section{Distribución de la población brasileña bajo el enfoque de las ciudades de porte medio}

\section{Resumen}

la desconcentración industrial, la movilidad de la frontera agrícola y las inversiones en infraestructura que integraron el interior de Brasil a la dinámica de la economía nacional son apuntados como algunos de los factores responsables de la dispersión espacial de la población brasileña. El presente artículo muestra la evolución de las ciudades de tamaño medio en Brasil entre los períodos de 1970 a 2010 a partir de un enfoque poblacional. La metodología se caracteriza por la investigación documental. Durante la realización del estudio es posible observar que las ciudades de tamaño medio tienen una posición estratégica potencial para la continuidad de la desconcentración regional en Brasil. Los resultados mostraron que las ciudades de tamaño medio aumentaron su participación en la población total del país: lo que en 1970 estaba representado aproximadamente por un $18 \%$ de la población urbana, en 2010 llegó a abarcar poco más del 27\% de esa población.

Palabras clave: Población urbana; Ciudades de tamaño medio; Sistema urbano, Brasil. 


\section{Notas}

1 Segundo Santos (1999, p. 17) “a racionalidade, neste fim de século, chega ao território; ou seja, ela não é apenas uma categoria da sociedade, da economia, da política. O próprio território em certos lugares acaba por tornar-se racional. Racional dessa racionalidade sem razão. Haveria uma produtividade espacial. Dentro de um certo tipo de economia hegemônica há espaços que são mais produtivos do que outros, e assim ter-se-ia que medir, ou ao menos considerar, produtividades espaciais diferentes segundo os lugares, o que tornaria possíveis participações diferentes no processo global”.

2 Segundo Santos (1994, p. 75), “a evidência empírica nos permite falar, no Brasil, de "involução metropolitana” devida, em boa parte, à capacidade de atração dos pobres pela metrópole, aonde vem engrossar uma demanda de empregos formais e de serviços urbanos que a cidade do capital monopolista não atende".

3 Ao largo de suas costas, no oceano Atlântico, há um forte polo de exploração de petróleo e gás natural pela Petrobras, na plataforma continental. A cidade é a maior produtora de petróleo do Brasil, além de concentrar a maior parte da indústria cerâmica fluminense.

4 Num processo de difusão espacial percolativa, apesar das forças de propagação atingir todo o território, o processo de desenvolvimento econômico continua desigual (FERRERA DE LIMA, 2004 apud TSCHÁ et al., 2009).

\section{Referências}

AMORIM FILHO, O. Cidades médias do Brasil. Revista Geografia e Ensino. Belo Horizonte: IGC/UFMG, v. 3, n. 2, 1984.

AMORIM FILHO, O.; SERRA, R. V. Evolução e perspectivas do papel das cidades médias no planejamento urbano e regional. In: ANDRADE, T. A.; SERRA, R. V. (Org.) Cidades médias brasileiras. Rio de Janeiro: IPEA, 2001. p. 1-34.

ANDRADE, T. A.; SERRA, R. V. Distribuição espacial do emprego e do produto industrial na década de 90: possibilidades atuais para a sua investigação. In: ANDRADE, T. A.; SERRA, R. V. (Org.) Cidades médias brasileiras. Rio de Janeiro: IPEA, 2001a. p. 337-393.

ANDRADE, T. A.; SERRA, R. V. O desempenho das cidades médias no crescimento populacional brasileiro no período 1970/2000. In: ANDRADE, T. A.; SERRA, R. V. (Org.) Cidades médias brasileiras. Rio de Janeiro: IPEA, 2001b. p. 129-170.

BAENINGER, R. A. Novos Espaços da Migração no Brasil: Anos 80 e 90. In: XII Encontro nacional de estudos populacionais da ABEP. Caxambu. Anais... Belo Horizonte: ABEP, v. 1, 2000.

BERNARDES, A. Cidades Médias. 2003. Disponível em: <http://www.mre.gov.br/cdbrasil/itamaraty/web/port/consnac/ocupa/procurb/cmedias/index.htm> Acesso em: 12 jul. 2004.

BRAGA, R. Cidades médias e aglomerações urbanas no Estado de São Paulo: novas estratégias de gestão territorial. In: X Encontro de Geógrafos da América Latina. Anais... São Paulo, 2005.

BRITO, F.; HORTA, C. J. G.; AMARAL, E. F. L. A urbanização recente no Brasil e as aglomerações metropolitanas. Trabalho publicado pela Associação Brasileira de Estudos Populacionais - ABEP - GT Migração, 2001. Disponível em: <http://www.abep.org.br/ usuario/GerenciaNavegacao.php?caderno_id=362\&nivel=1\&texto_id=2092>. Acesso em: $18 \mathrm{dez} .2004$.

CASTELLS, M. A questão urbana. Rio de Janeiro: Paz e Terra, 1983.

CHRISTALLER, W. Central place in southern Germany. New Jersey: Prentice-Hall, 1966 
CEPAL - Comissão Econômica para América Latina e o Caribe. El rostro de la urbanización en América Latina y el Caribe. Serviço de informação da Cepal - Comunicado de imprensa. In: CONFERENCIA REGIONAL SOBRE EL PROGRAMA DE HÁBITAT. Chile, 2000. Disponível em: <http://www.eclac.cl/cgi-bin/getProd.asp?xml=/ prensa/noticias/comunicados/1/5041/P5041. xml\&xsl=/prensa/tpl/p6f.xsl>. Acesso em: 20 abr. 2013.

DAVIS, M. Planeta favela. Tradução Beatriz Medina. São Paulo: Boitempo, 2006.

DINIZ, C. C. Desenvolvimento poligonal no Brasil: nem desconcentração, nem contínua polarização. Nova Economia, Belo Horizonte, v. 3, n. 1, p. 35-64, set., 1993.

FERRERA DE LIMA, J. La diffusion spatiale du développement économique régional: L'analyse des composantes et de la forme de la diffusion spatiale au Sud du Brésil au XX $X^{e}$ siècle. Thèse de doctorat en développement régional, DSH/Université du Québec à Chicoutimi, Saguenay. Disponível em:<http://www.irec.net/01fr_rechercheaffiche.php3?518>.

FRIEDMAN, J. A General Theory of Polarized Development. In: HANSEN, N. (Ed.), Growth Centres in Regional Development. New York: The Free Press, p. 29-41, 1972.

GEDDES, P. Cidades em evolução. (Coleção ofício de arte e formas) Campinas: Papirus, 1994.

HAESBAERT DA COSTA, R. O mito da desterritorialização: do "fim dos territórios" à multiterritorialidade. Rio de Janeiro: Bertrand Brasil, 2004. 400p.

IBGE. Instituto Brasileiro de Geografia e Estatística. Estimativas das populações dos municípios em 2011. IBGE: Rio de Janeiro, 2011. Disponível em: <http://www.ibge.gov.br/home/presidencia/noticias/noticia_visualiza.php?id_noticia=1961\&id_pagina=1>. Acesso em: 26 ago. 2012. . Estatísticas do século XX. Cd-Rom, 2003.

Sistema de informações recuperadas georeferenciadas - Estatcart: base de informações. [Cd-rom]. Rio de Janeiro: IBGE, 2002.

. Censo Demográfico. Rio de Janeiro: IBGE, 1970, 1980, 1991, 2000 e 2010.

IPEA/UNICAMP.IE.NESUR/IBGE. Caracterização e tendências da rede urbana do Brasil. IPEA/ Unicamp-IE-Nesur/IBGE. Campinas: Unicamp.IE, 1999.

KON, A. Novas territorialidades: transformações nas hierarquias econômicas regionais. Revista Pesquisa e Debate. São Paulo, v. 10, n. 1(15), p. 42-76, 1999.

KRUGMAN, P. Increasing returns and economic geography. Journal of Political Economy, Washington (DC), n. 99, p. 483-499, 1991.

KRUGMAN, P.; VENABLES, A.; FUJITA, M. Economia espacial. São Paulo: Futura, 2004.

LACOUR, C. et GACHET, F. Métropolisation, centre et centralité. Revue d'Économie Régionale et Urbaine (RERU), Bordeaux, n. 1, p. 49-72, 2002.

LIMA, R. S. Expansão urbana e acessibilidade: o caso das cidades médias brasileiras. (Dissertação de Mestrado) Universidade de São Paulo - Escola de Engenharia de São Carlos. São Carlos: USP, 1998.

MARICATO, E. Brasil, cidades: alternativas para a crise urbana. Petrópolis, RJ: Vozes, 2001.

MUMFORD, L. A cidade na história: suas origens, transformações e perspectivas. 2. ed. São Paulo: Martins Fontes, 1982.

Teoria e Evidência Econômica - Ano 23, n. 49, p. 381-406, jul./dez. 2017 
PEREIRA, A M. A propósito das cidades médias: algumas considerações sobre Montes Claros. In: SIMPÓSIO INTERNACIONAL CIDADES MÉDIAS: DINÂMICA ECONÔMICA E PRODUÇÃO DO ESPAÇO URBANO - CIMDEPE, I. Anais... Presidente Prudente: Unesp, 2005.

PERLMAN, J. E. O mito da marginalidade: favelas e políticas no Rio de Janeiro. Rio de Janeiro: Paz e Terra, 1977.

SANTOS, M. A nova urbanização: diversificação e complexidade. In: SANTOS, Milton. A urbanização brasileira. 5. ed. São Paulo: Hucitec, 2005, p. 53-61.

- O território e o saber local: algumas categorias de análise. Cadernos IPPUR. Rio de Janeiro, Ano XIII, n. 2, 1999, p. 15-26.

A região cresce mais que a metrópole. In: SANTOS, Milton. Por uma economia política da cidade. São Paulo: Hucitec, Editora PUC-SP, 1994, p. 53-77.

SCHAPIRA, M. F. P. Amérique latine: La ville fragmentée. In: DONZELOT, J. (Org.) Quand la ville se défait. Esprit, novembre, 1999, p. 128-144.

SILVEIRA, R. L. L. Cidade, corporação e periferia urbana: acumulação de capital e segregação espacial na (re) produção do espaço urbano. Santa Cruz do Sul: Edunisc, 2003.

STAMM, C. Determinantes do movimento de trabalhadores pendulares na Aglomeração urbana do Nordeste do Rio Grande do Sul: uma análise a partir dos transportes coletivos. Tese (Doutorado em Planejamento Urbano e Regional) - Universidade Federal do Rio Grande do Sul. Porto Alegre, 2013. Disponível em: <http://www.lume.ufrgs.br/bitstream/handle/10183/71909/000879545. pdf?sequence=1>. Acesso em: 19 maio 2016.

STAMM, C. O fenômeno dos movimentos pendulares dos trabalhadores intermunicipais entre cidades de porte médio: o caso de Cascavel e Toledo (PR). 2005. Dissertação (Mestrado em Desenvolvimento Regional e Agronegócio) - Universidade Estadual do Oeste do Paraná - Unioeste/ Campus de Toledo. Disponível em: <http://tede.unioeste.br/tede//tde_arquivos/ 2/TDE-2006-0606T173530Z-24/Publico/Dissertacao\%20Cristiano\%20Stamm\%20p1.pdf >. Acesso em: 3 maio 2016.

STAMM, C.; PIFFER, M.; PIACENTI, C. A. Análise dos fatores que influenciaram a localização das indústrias no Estado do Paraná. In: CONGRESSO BRASILEIRO DE ECONOMIA E SOCIOLOGIA RURAL, XLII. Cuiabá. CONGRESSO BRASILEIRO DE ECONOMIA E SOCIOLOGIA RURAL - DINÂMICAS REGIONAIS E DESENVOLVIMENTO REGIONAL, XLII. Brasília: Sober, 2004. p. 271-271.

SOARES, P. R. R. Cidades médias e aglomerações urbanas: a nova organização do espaço regional no Sul do Brasil. In: SIMPÓSIO INTERNACIONAL CIDADES MÉDIAS: DINÂMICAS ECONÔMICAS E PRODUÇÃO DO ESPAÇO URBANO - CIMDEPE, I. Anais... Presidente Prudente: Unesp, 2005. 